\title{
REVISIÓN BIBLIOGRÁFICA SOBRE LA EVOLUCIÓN DE LAS “IDEAS” DE LOS ALUMNOS SOBRE EL CONCEPTO DE FUERZA EN SITUACIONES DE EQUILIBRIO ESTÁTICO
}

\author{
Enrique Jiménez Gómez* \\ Nicolás Martín Martínez \\ Isabel Solano Martínez
}

\begin{abstract}
The aim of this paper is to analyse current views on learners' "ideas" concerning the concept of force in situations of sta tic equiibrium.

To do this, a large sample of articles on this subject has been reviewed and a set of categories establihed which allow the comparison of the information presented in these selected articles.
\end{abstract}

KEYWORDS: Learners' "ideas”, Force, Static equilibrium.

\begin{abstract}
RESUMEN
En este trabajo se pretende analizar la situación actual de las "ideas" de los alumnos sobre el concepto de fuerza cuando se le plantean situaciones de equilibrio estático.

Para ello, se ha tomado una muestra amplia de trabajos y se han establecido una serie de categorías para unificar criterios y hacer comparables los datos aportados por los diferentes trabajos seleccionados.
\end{abstract}

Palabras claves: "Ideas" de los alumnos, Fuerza, Equilibrio estático.

\footnotetext{
Profesor Titular de Facultad de la universidad de Murcia. Departamento de Didáctica de Ciencias Experimentales. Facultad de Educación. Campus Universitario de Espinardo. 30100 Murcia. España.

* Profesor Titular de Facultad de la Universidad de Almeria. Departamento de Didáctica de la Matemática y de las Ciencias Experimentales. Facultad de Humanidades y Ciencias de la Educación. Cañada de San Urbano. Almería. España.

Profesor-Ayudante de Facultad de la Universidad de Murcia. Departamento de Didáctica de Ciencias Experimentales. Facultad de Educación. Campus Universitario de Espinardo. 30100 Murcia. España.
} 


\section{INTRODUCCIÓN}

Previa a la realización del diseño de instrucción para que los alumnos aprendan el concepto de fuerza y aquellos otros con él relacionados, se ha hecho una revisión bibliográfica de las "ideas" previas a la enseñanza que tienen los alumnos sobre dicho concepto. La diversidad de resultados encontrados en dicha revisión, tanto en lo referente a la descripción e interpretación de las respuestas de los sujetos como en la metodología empleada, nos ha llevado a realizar este trabajo, que consiste en estudiar:

a) Si ha existido evolución o progreso en este tipo de trabajos a lo largo de los años.

b) Las tendencias o direcciones más significativas que han existido en los mismos.

Para ello, se analizan los trabajos publicados sobre "ideas" de los alumnos sobre fuerza, con el fin de ponderar si el catálogo de concepciones sobre esta noción es un tema acabado. De no ser así, ¿en qué dirección habría que trabajar para obtener nuevos datos?

\section{SELECCIÓN DE UNA MUESTRA DE TRABAJOS REPRESENTATIVOS DE LAS INVESTIGACIONES REALIZADAS}

El primer problema consiste en seleccionar una muestra de trabajos que fuese representativa de la investigación realizada sobre "ideas" de los alumnos relacionadas con el concepto de fuerza y que, además, permitiese poner de manifiesto si ha existido progresión a lo largo de los años en la delimitación de dichas ideas. Para ello, se seleccionaron las siguientes revistas, ordenadas alfabéticamente, que resultaron accesibles para nosotros y que, además, cubren el objetivo del trabajo:

1. Enseñanza de las Ciencias (1983- 1985. El Primer número apareció en 1983).

2. European Journal of Science Education, hoy: International Journal of Science Education (1 979-1 995. El primer número que se ha conseguido es del año 1979).

3. Physics Education (1 975-1 995)

4. Science Education (1975-1995).

Al ser excesivo el número de publicaciones, se han seleccionado para este trabajo sólo aquellas que tratan el concepto de fuerza y además, en los cuestionarios, se presentan situaciones de equilibrio estático. En total la muestra está constituida por 17 artículos y aunque pudiera faltar alguno, debido a problemas de búsqueda informatizada en el caso de que los autores hayan utilizado palabras claves que no evoquen nuestro contenido de búsqueda, creemos que es una muestra significativa, entre otras razones, porque se encuentran los más referenciados.

Los artículos seleccionados, ordenados por orden cronológico de publicación, aparecen en la tabla 1, donde también se exponen las pretensiones de cada uno de ellos, la muestra utilizada y la técnica de recogida de datos.

Para poner de manifiesto si ha existido evolución o progreso en los trabajos anteriores en el tiempo, se ha dividido el número de ellos en dos periodos. El primero, desde 1975 a 1985 (no se han encontrado artículos publicados acerca del concepto de fuerza en cuyos cuestionarios figuren situaciones de equilibrio estático hasta el año 1980) y el segundo, 
desde 1985 a 1995. En el primer periodo han aparecido nueve trabajos y en el segundo ocho.

\section{CRITERIOS DE COMPARACIÓN}

Si se observa la tabla del anexo 1, se puede apreciar la diversidad de pretensiones $u$ objetivos, muestras y técnicas de recogida de datos en los diferentes trabajos (se presentan unas 10 maneras diferentes de obtener datos). Esta heterogeneidad dejó entrever la dificultad de realizar estudios comparativos y, sobre todo, la necesidad de hacer agrupamientos, en función de semejanzas y diferencias del tipo de aportaciones sobre las "ideas" de los alumnos sobre el concepto de fuerza.

Del análisis de la tabla 1, del tratamiento que los diferentes autores hacen de los datos y de los resultados que ofrecen (algunos de los cuales se exponen en las tablas de los anexos 2 y 3), se puede apreciar que, para algunos autores, las "ideas" de los alumnos acerca del concepto de fuerza son las explicaciones que realizan los alumnos sobre un determinado hecho físico, mientras que para otros son explicaciones o razonamientos independientes de dichos hechos. Por esta razón, se han establecido dos tipos de categorías, según que los autores:

1. Identifiquen y describan las respuestas de los alumnos y las agrupen por semejanzas o diferencias entre ellas, expresando los resultados mediante porcentajes de alumnos que han respondido de una manera u otra, de modo que los resultados y conclusiones están ligados a las particularidades de los hechos físicos presentados en el cuestionario; a este grupo de trabajos los hemos denominado descriptivos dependientes de los hechos físicos, y con estos términos se hará referencia más adelante a esta categoría.

2. Después de identificar y describir las respuestas de los alumnos, establezcan relaciones entre dichas respuestas referentes a las distintas preguntas realizadas y a los hechos físicos presentados. El grado de generalidad de las conclusiones a las que se llegan hace que los resultados que se ofrecen no estén ligados a dichos hechos, e incluso, algunos autores, pueden predecir posibles respuestas de los alumnos a situaciones no presentadas en el cuestionario. La abstracción de los datos se hace desde la lógica del contenido objeto de búsqueda, en nuestro caso, los relacionados con el concepto de fuerza, su evolución histórica y conceptos con ella relacionados. Nos referiremos a estos trabajos con los términos descriptivos independientes de los hechos físicos.

En la tabla 1 se presentan las dos categorías establecidas en las que se pueden distribuir todos los trabajos seleccionados sobre Equilibrio Estático. Las categorías y la clasificación de los diferentes trabajos se han realizado a partir del análisis de las pretensiones u objetivos, tratamiento de los datos y resultados ofrecidos en cada una de las publicaciones seleccionadas.

Tabla 1: Distribución por categorías de los trabajos seleccionados.

\begin{tabular}{|l|l|l|}
\hline Año & Descriptivos dependientes & Descriptivos independientes \\
\hline$<85$ & $\begin{array}{l}\text { Helm, 1980; Gunstone y White, } \\
\text { 1981; Watts y Zylbersztajn, 1981; }\end{array}$ & $\begin{array}{l}\text { Watts, 1982; Walts, Waney, 1984; Ruggiero } \\
\text { Magitalizado por RED ACADEMICA }\end{array}$ \\
\hline
\end{tabular}




\begin{tabular}{|l|l|l|}
\hline & Ivowi, 1984 & y otros, 1985; Terry y otros, 1985. \\
\hline$>85$ & $\begin{array}{l}\text { Terry y Jones, 1986; Clement y } \\
\text { Otros, 1989; Bar, 1989; Kruger y y } \\
\text { otros, 1992 }\end{array}$ & $\begin{array}{l}\text { Brown, 1989; Finegold y Gorsky, } \\
\text { 1991; Thies, 1992; Kuiper y } \\
\text { Mondlane, 1994. }\end{array}$ \\
\hline
\end{tabular}

Esta primera categorización permite comparar datos entre los diferentes autores que están clasificados dentro de cada una de ellas.

\section{ESTUDIO COMPARATIVO DE LOS TRABAJOS SELECCIONADOS SOBRE "IDEAS" DE LOS ALUMNOS}

\subsection{Resultados dependientes de los hechos físicos presentados}

En todos los trabajos los autores realizan descripciones de las respuestas de los alumnos y clasifican y analizan dichas respuestas desde el contenido académico objeto de búsqueda. Esto podría justificar el que los autores sólo describan las respuestas de los alumnos en términos de conceptos erróneos o ideas falsas (Helm 1980), nivel de comprensión correcta o incorrecta (Gunstone y White 1981), concepciones erróneas (Ivowi, 1984; Kruger y otros, 1992), concepción errónea o ausencia de comprensión (Terry y dones, 1986).

Clement y otros (1989) presentan un enfoque distinto, pues sus objetivos son diferentes, ya que intenta descubrir anclajes para la instrucción en Física. Considera que los alumnos, previo a la instrucción, sostienen algunas ideas que son bastante coincidentes con la Teoría Física aceptada y centra su estudio en la posibilidad de identificar tales intuiciones positivas.

Bar (1989) utiliza como criterio de clasificación las etapas del pensamiento proporcional definidas por Karplus y Peterson (1980) y por ello habla de respuestas cualitativas, de esquema aditivo, de tipo multiplicativo-aditivo, de tipo multiplicativo y especial.

En la tabla del anexo 2 se puede observar que no se producen nuevos datos, si se comparan los trabajos del segundo periodo respecto del primero, más que los que derivan de las diferentes situaciones o hechos físicos y preguntas realizadas a los encuestados, extremo que pudiera resultar obvio, dado que todos los autores referenciados en dicha tabla sólo describen las respuestas de los alumnos.

\subsection{Resultados independientes de los hechos físicos presentados}

Esquemas referidos al concepto de fuerza en situaciones de equilibrio estático

A) Período 75-85: En este periodo aparecen los siguientes esquemas:

1. Los objetos retenidos en una posición tienen fuerza. Tiene un sentido similar a la idea del físico de energía potencial (Watts 1983). 
2. Fuerza como propiedad de una sustancia que es transmitida a todas las partes de la misma y que actúa en la superficie con otros objetos. Necesita alguna sustancia a través de la cual operar. Es similar a la noción física de presión (Watts, 1983).

3. Hay fuerzas presentes cuando tiene lugar una actividad a gran escala (Watts, 1983).

4. No existen fuerzas sobre objetos en reposo (Gilbert y Watts, 1983, citado por Finegold y otros, 1991).

5. La masa más grande ejerce la fuerza más grande (Maloney, 1984).

Además de los esquemas obtenidos por los diferentes autores del primer periodo, Maloney (1984) determina las posibles reglas (modelos o estrategias de razonamiento) que utilizan los individuos a la hora de comparar las fuerzas que ejercen dos cuerpos entre sí en función del estado del sistema (reposo, movimiento con velocidad constante o con aceleración constante), constituido por dos cuerpos adosados o enganchados, considerando todas las posibilidades que resultan de variar la masa de los bloques y el bloque que está empujando o tirando en el caso de que exista movimiento. Establece categorías en función del estatus que se asigne a los distintos estados y dentro de las mismas, determina las reglas que tienen en cuenta las $2 / 3$ partes de las respuestas.

Además, Ruggiero y otros (1985) apuntan la posibilidad de que existan esquemas diferentes para equilibrio dependiendo del hecho físico (una barra suspendida de su centro de gravedad, objetos en una polea...), por lo que apunta a la necesidad de realizar nuevos estudios.

B) En el período 85-95, aparece sólo el siguiente esquema:

En situaciones de reposo, cuando se considera que hay más de una fuerza, una de ellas es dominante. (Thijs, 1992).

Si se comparan los dos periodos (1 975-1985 con el 1985-1 995), la progresión viene determinada no por el aumento en cuanto a descubrimiento de nuevos esquemas, sino por la realización de estudios evolutivos y de consistencia para:

a) Evaluar si un esquema o regla se aplica para determinar las fuerzas actuantes sobre objetos en reposo en distintos contextos. Por ejemplo, en alumnos que habían estudiado una Física muy general o que no habían estudiado Física, no hay ley o leyes generales que gobiernen su pensamiento sobre situaciones de equilibrio estático. Como señalaba Reif (1987) parece que existen reglas específicas para situaciones específicas (una ley de fuerzas para objetos en reposo sobre superficies, otra para objetos suspendidos de una cuerda, etc), pero no existe consistencia o generalidad a la hora de aplicar dichas leyes (Finegold y Gorsky, 1991).

b) Determinar si la misma idea de fuerza era utilizada en distintas áreas problema (reposo (A), objetos en movimiento (B), objetos lanzados (C) o colisiones (D)). Al parecer, si se modifica el contexto o el problema, Kuiper y Modlane (1994) encuentran que la idea de fuerza usada en el área problema A es a menudo inconsistente con la usada en las otras áreas. Describir este tipo de comprensión como un esquema alternativo para fuerza daría la impresión errónea de coherencia en las ideas de los estudiantes. 
De la tabla del anexo 3 se infiere, por tanto, que no han aparecido nuevos esquemas alternativos para el concepto de fuerza, salvo el deducido por Thijs (1992), en el periodo 1985-95. En cambio, sí aparecen en este segundo periodo, controversias acerca de la existencia de verdaderos esquemas (explicaciones de los alumnos que tienen la característica de la repetición, generalización y diferenciación, Jiménez Gómez, Solano y Marín, 1994) sobre el concepto de fuerza, cuando se trata de que respondan los encuestados a preguntas referidas a situaciones o hechos de equilibrio estático.

Lo anterior, pone de manifiesto que los estudios realizados sobre lo que "el alumno sabe' sobre el concepto de fuerza no es un tema acabado y que requiere de nuevas investigaciones para clarificar si dicho contenido tiene significado para los alumnos o no, y para qué edad o edades (Jiménez Gómez y Marín, 1996). En caso de ser significativo, determinar los esquemas explicativos (Jiménez Gómez, Solano y Marín, 1994) que tienen los alumnos de los diferentes niveles educativos.

Krugger y otros (1992) detectan el problema de significación, incluso para grupos de profesores no especialistas. Así, cuando cambian el tipo de situación física, referidas a situaciones o hechos físicos de equilibrio estático, obtienen los siguientes resultados:

a) Muchos profesores no estaban seguros de qué se considera como fuerza en situaciones estáticas.

b) Muchos profesores no reconocen la fuerza de reacción que una mesa o el suelo ejerce sobre los objetos.

c) $25 \%$ de la muestra rechaza la existencia de la fuerza de reacción en todas las situaciones del cuestionario y por encima del 50\% también rechaza su existencia en el caso de un coche estacionario.

d) Sobre el $40 \%$ estaba inseguro del estatus del peso como fuerza o rechazaba que era una fuerza. Más de la mitad no identificaba peso con gravedad.

e) La idea de fuerza neta era nueva para muchos profesores.

Ante los datos que ofrecen los distintos investigadores parece deducirse que el significado que se le asigna al concepto de fuerza deducido de los principios de la dinámica, para situaciones de equilibrio estático, no es muy significativo para los alumnos y profesores entrevistados por Krugger y otros (1990).

También se podría cuestionar la aplicación del Tercer Principio a situaciones de equilibrio estático. Así, si se está de acuerdo con el Tercer Principio, ¿dónde está la fuerza en el dinamómetro cuando se cuelga un objeto que ha alcanzado el equilibrio estático o qué fuerzas se ponen en juego cuando se deja un libro en reposo sobre una mesa si se considera la fuerza como la variación infinitesimal de la cantidad de movimiento respecto al tiempo?

Estas y otras cuestiones permiten establecer un debate que pudiera dar sentido a las explicaciones de los alumnos y de los profesores. Así, ¿serían iguales los resultados obtenidos por los diferentes investigadores si en sus preguntas en vez de figurar el concepto de fuerza o del tercer principio de la dinámica, permitiesen a los alumnos explicar las situaciones físicas en función de sus esquemas y desde su propia interpretación del mundo que les rodea? 


\section{CONCLUSIONES}

De todo lo expuesto se pueden extraer, entre otras, las siguientes conclusiones referidas al concepto de fuerza que tienen los alumnos cuando se les pregunta acerca de situaciones o hechos físicos de equilibrio estático:

1. Se puede apreciar que tanto en los trabajos dependientes e independientes de los hechos físicos presentados, no parece haber una evolución significativa en cuanto a aportaciones novedosas sobre la noción de fuerza. No se han encontrado, como en otros tópicos (Jiménez Gómez, Solano y Marín, 1997), trabajos en los que se tengan en cuenta variables cognitivas de alumno, relacionándolas con las "ideas" de los alumnos, excepto Bar (1989) que sí establece dichas relaciones entre las respuestas de los alumnos y su pensamiento proporcional. Tampoco aparecen trabajos donde los datos que aporta el alumno sean tratados desde un entramado teórico más cercano al modo en que el alumno organiza su conocimiento. No parece que el contenido de enseñanza sea el referente más adecuado para interpretar los datos del alumno, si tenemos en cuenta las diferencias entre el conocimiento científico y el cotidiano, así como, interpretar desde la Ciencia las respuestas de los alumnos que proceden de su estructura cognoscitiva.

2. De las tablas de los anexos 2 y 3 , no se infiere que los trabajos progresen desde los dependientes a los independientes de los hechos físicos presentados. A lo largo de los 20 años en el que se han llevado a cabo los trabajos no parecen existir progresos en cuanto a la metodología de investigación referida a la identificación y descripción de las "ideas de los alumnos", es decir, se siguen realizando trabajos de idénticas características en los años 80-85 que en el 85-95 y sólo se puede saber si un artículo es de uno u otro periodo por la fecha de publicación, pero no por las características metodológicas o la progresión en cuanto a los resultados presentados por los diferentes autores.

Resulta ilustrativo, como ejemplo del poco progreso en cuanto a la metodología de investigación de "lo que el alumno sabe" sobre fuerza, el que todos los autores, a excepción de Gunstone y White (1981), utilicen en las preguntas que realizan a los encuestados el término fuerza o tercer principio de la dinámica. De ahí que, al enfatizar el significante "fuerza", las respuestas del alumno estén mediatizadas, según nuestro criterio, por la propia pregunta; se podría haber evitado este sesgo si se hubiera enfrentado al alumno con situaciones físicas donde se hubiese puesto en juego la noción de "fuerza" de un modo implícito, en las que demandase explicaciones, previsiones, soluciones, sin implicar explícitamente el significante, de manera que, el alumno hubiese tenido que generar una respuesta sin haberle dado opción a reconsiderar el hecho físico presentado desde una perspectiva diferente a la que se deduce del marco teórico actual de la mecánica clásica.

3. La búsqueda de las "ideas" de los alumnos no suele estar guiada por determinados supuestos teóricos; el único referente que guía los diseños de los cuestionarios y la interpretación de los datos es el propio contenido de enseñanza cuyas concepciones se desean delimitar en el alumno. Sin embargo, referentes más apropiados que hayan estudiado con profundidad y extensión la cognición del alumno, como es el caso de la Epistemología Genética, son ignorados sistemáticamente.

4. No han aparecido nuevos esquemas alternativos sobre el concepto de fuerza (situaciones de equilibrio estático) a partir del año 1985, excepto uno obtenido por Thijs (1992). Sin embargo, sí aparecen en el período 1985-95 controversias acerca de si 
existen o no en los alumnos verdaderos esquemas explicativos sobre el concepto de fuerza, cuando se trata de que respondan a preguntas referidas a situaciones o hechos de equilibrio estático, lo que invita a sospechar que ha existido cierto "relajamiento metodológico" en este segundo periodo.

Lo anterior, indica que el tema de las "ideas" de los alumnos habría que abordarlo desde una perspectiva más amplia, que permitiera determinar al educador:

a) Si en las situaciones de equilibrio estático presentadas a los alumnos en las que subyace el concepto de fuerza, son significativas para los sujetos entrevistados. En este sentido, es necesario ponderar desde el análisis de la estabilidad y significación de las respuestas del alumno, el grado de significación de las situaciones (Jiménez Gómez y Marín, 1996).

b) Los momentos claves (edad, por ejemplo) en los cuales los alumnos pasan espontáneamente de la globalización del concepto de fuerza a su diferenciación, por lo que sería necesario realizar estudios de carácter evolutivo relativos a dicho concepto.

c) Las limitaciones en las capacidades cognitivas de los sujetos para aprender un determinado concepto, en este caso el de fuerza y conceptos con ella relacionados.

d) Tratar de ajustar las actividades de enseñanza a las características cognitivas, motivacionales y afectivas del alumno, que sólo es posible realizar si se conoce del sujeto toda aquella información significativa del alumno de interés didáctico, tanto si está relacionada con el contenido académico como si no lo está (Piaget y García, 1973; Marín, 1994). En efecto, destrezas motoras e intelectivas (manipulación de material didáctico, control de variables, razonamiento proporcional, etc. ...), habilidades en el tratamiento de datos empíricos (observar, clasificar, seriar, etc. ...), capacidades para realizar inferencias, nivel cognoscitivo, son factores que, sin duda, serían de gran utilidad didáctica, más aún si pretendemos objetivos de enseñanza enmarcados en la LOGSE.

Llegar a solucionar los puntos anteriores requiere, previamente, que los educadores e investigadores clarifiquen cuestiones elementales y útiles de cara a conseguir una progresión en este tipo de estudios, tales como: ¿la conceptualización del tercer principio de la dinámica permite explicar a los alumnos de diferentes niveles educativos, de forma útil y fructífera, las situaciones físicas de equilibrio estático?, ¿qué entiende cada educador o investigador por "lo que el alumno sabe" sobre un determinado contenido de enseñanza?, ¿qué marco teórico ofrece una metodología de investigación adecuada para identificar, describir e interpretar las respuestas de los alumnos?

En vista de lo anterior, no parece que la afirmación: "el catálogo de concepciones sea bastante completo y habría que dedicar los esfuerzos en otras direcciones" sea acertada.

Una simple comparación entre los trabajos sobre concepciones del constructivismo social y las experiencias de Piaget de los años 50, 60 y 70 (véase Marín y Benarroch, 1994) obliga a reflexionar sobre el supuesto progreso que supuso la primera tendencia para la enseñanza de las Ciencias (véase Gilbert y Swift, 1985) e invita a buscar un contexto teórico más adecuado del que hasta el momento se viene empleando de una forma mayoritaria para llevar a cabo este tipo de estudios. 
Ahora bien, se percibe desde hace unos años acá que algo parece estar cambiando en la visión que se posee sobre las concepciones del alumno. Así, parece existir cierta tendencia, no generalizable a toda la comunidad del ámbito, a reflexionar críticamente sobre el tema de las concepciones en varias direcciones:

Desplazamiento del interés por las concepciones alternativas, ideas previas, etc. como regularidades de las respuestas del alumnado hacia los constructos como modelos mentales, esquemas y teorías implícitas que explicarían, en última instancia, las concepciones (Vosniadou, 1994; Pozo y Gómez Crespo, 1998; Oliva, 1999).

- Cuestionamiento de los fundamentos metodológicos (Gutiérrez y Ogborn, 1992; Vosniadou y Brewer, 1992; 1994; Benarroch, 1998).

- Aumento significativo de estudios evolutivos (por ejemplo, Galili y Bar, 1992; Reynoso y otros, 1993; Bar y otros, 1994; Kuiper y Mondlane, 1994: Montanero y Pérez, 1995).

- Preocupación por una fundamentación teórica más allá del pragmatismo e inductivismo que caracterizaron a las primeras investigaciones en esta línea (Vosniadou, 1994; Lawson, 1994; Moreira, 1994; Glynn y Duit, 1995; Pozo y Gómez Crespo, 1998; Vosniadou y loannides, 1998; Marín, 1998).

Se están abriendo nuevas tendencias y perspectivas para abordar el estudio del conocimiento del alumnado que sugieren estar expectantes sobre el nuevo rumbo a tomar.

\section{REFERENCIAS BIBLIOGRÁFICAS}

Bar, V. (1989). Introducing mechan/os at the elementaiy school. Physics Education, 24, 348-352.

Bar, y.; Zinn, B.; Goldmuntz, R. y Sneider, O. (1994). Children's concepts about weight and free fall. Sc/ence Education, 78(2), pp. 149-169.

Benarrich, A. (1998). Las explicaciones de los estudiantes sobre las manifestaciones corpusculares de la materia, (tesis inédita), Facultad de Educación (Universidad de Granada).

Brown, D.E. (1989). "Students' concept of force: the importance of understanding Newton's third law". Physics Education, 24, 352-358.

Clement, J.; Brown, D.E. y Zietsman, A. (1989). "Not all preconceptions are misconceptions: finding 'anchoring conceptions' for grounding instruction on students' intuitions". International Journal of Science Education, 11, special issue, 554-565.

Finegold, M.y Gorsky, P. (1991). "Students' concepts of force as applied te related physical systems: A search for consistency". International Journal of Science Education, 13 (1), 97-113. 
Galili, I. y Bar, V. (1992). Motion implies Force: where te expect vestiges of the misconception? International Journal of Science Education, 14(1), pp. 63-81.

Gilbert, J. K. y Swift, D. J. (1985). "Towards a lakatosian analysis of the piagetian and alternative conoeptions research programs”. Sc/ence Education, 69(5), pp. 681 -696.

Glynn, G. M. y Duit, R. (eds). (1995). Learning science in schools. Hillsdale, N.J.: Erlbaum.

Gutiérrez, R. y Ogborn, J. (1992). "A causal framework for analysing alternativo conceptions". International Journal of Science Education, 14(2), pp. 201-220.

Gunstone, R. F. y White, R. T. (1981). "Understanding of gravity". Science Education, 65 (3), 291-299.

Helm, H. (1980): "Misconoeptions in physics amongst South African students". Physiscs Education, 15, 92-105.

Ivowi, U.M.O. (1984). "Misconceptions in physics amongst Nigerian secondary school students". Physics Education, 19, 279-285.

Jiménez Gómez, E., Solano, I. y Marín, N. (1994). "Problemas de terminología en estudios realizados sobre 'lo que el alumno sabe' en Ciencias". Enseñanza de las Ciencias, 12 (2), 235-245.

Jiménez Gómez, E. y Marín, N. (1996). “¿Cuando un contenido académico tiene significado para el alumno? Implicaciones didácticas". Enseñanza de las Ciencias, 14(3), pp. 323-330.

Jiménez Gómez, E., Solano, I. y Marín, N. (1997). "Evolución de la progresión de la delimitación de las 'ideas' de alumno sobre fuerza”. Enseñanza de las Ciencias, 15(3), pp. 309-328.

Kruger, C., Palacio, D. y Summers, M. (1992). "Surveys of English Primary Teachers' Conceptions of Force, Energy and Materials". Science Education, 76 (4), 339-351.

Kuiper, J. y Mondlane, E. (1994): "Student ideas of science concepts: alternative frameworks?". International Journal of Science Education, 16 (3), 279-292.

Lawson, A.E. (1994). "Uso de los ciclos de aprendizaje para la enseñanza de destrezas de razonamiento científico y de sistemas conceptuales". Enseñanza de las Ciencias, 12(2), pp. 165-187.

Maloney, D.P. (1984). "Rule-governed approaches te physios-Newton's third law". Physics Education, 19, 37-42.

Marín, N. (1994): Evolución de los esquemas explicativos en situaciones de equilibrio estático. Tesis Doctoral. Universidad de Granada.

Marín, N. (1998). Fundamentos de Didáctica de las Ciencias Experimentales. Almería: Servicio de Publicaciones de la Universidad de Almería. 
Marín, N. y Benarroch, A. (1994). "A comparative study of Piagetian and constructivist work en conceptions in science". International Journal of Science Education, 16(1), pp. $1-15$.

Montanero, M. y Pérez, AL. (1995). "A survey of students' understanding of colliding bodies". Physics Education, 30(5), pp. 277-283.

Moreira, M.A. (1994). "Diez años de la revista Enseñanza de las Ciencias: de una ilusión a una realidad”. Enseñanza de las Ciencias, 12(2), pp. 147-153.

Oliva, J.M. (1998). "Algunas reflexiones sobre las concepciones alternativas y el cambio conceptual”. Enseñanza de las Ciencias, 17(1), p. 93-115.

Piaget, J. y García, R. (1973). Las explicaciones causales. Barcelona: Barral.

Pozo, I. y Gómez Crespo, MA. (1998). Aprender y enseñar ciencia. Madrid: Morata.

Reynoso, H. E.; Enrique Fierro, H.; Gerrdo Torres, O.; Vicentini-Missoni, M. y Pérez de Celis, J, H. (1993). "The alternativo frameworks presented by Mexican students and teachers concerning the free fall of bodies". International Journal of Science Education, Vol. 15(2), pp. 127-138.

Ruggiero, S., Cartelli, A., Dupre, F. y Vicentini Missoni, M. (1985). "Weight, gravity and air pressure: Mental representations by tallan middle school pupils". European Journal of Science Education. 17 (2), 181-194.

Terry, C. y Jones, G. (1986). "Alternativo frameworks: Newton's third law and conceptual change". European Journal of Science Education, 8 (3), 291-298.

Terry, C., Jones, G. y Hurford, W. (1985). “Children's conceptual understanding of forces and equilibrium". Physics Education, 20, 162-1 65.

Thijs, G. D. (1992). "Evaluation of an Introductory Course en 'Force' considering students' preconceptions". Science Education, 76 (2), 155-174.

Vosniadou, S. (1994). "Capturing and modelling the process of conceptual chango". Learning and Instrucción, 4(1), pp. 45-69.

Vosniadou, S. y loannides, C. (1998). "From conceptual development te sicence education: a psychological point of view". International Journal of Science Education, 20(10), pp. 1213-1230.

Watts, D. M. (1982). “Gravity-don't take it for granted”. Physics Education, 17,116-121.

Watts, D. M. (1983). "A study of school children's alternativo frameworks of the concept of force". European Journal of Science Education, 5 (2), 217-230.

Watts, D. M. y Zylbersztajn, A. (1981). "A survey of sorne children's ideas about force". Physics Education, 16 (6), 360-365. 


\section{ANEXO 1: TRABAJOS SELECCIONADOS.}

\begin{tabular}{|c|c|c|c|}
\hline $\begin{array}{l}\text { Autor/es } \\
\text { año }\end{array}$ & $\begin{array}{c}\text { Pretensiones u objetivos } \\
\text { de trabajo }\end{array}$ & Muestra & $\begin{array}{c}\text { Técnica de recogida } \\
\text { de datos }\end{array}$ \\
\hline Helm, 1980 & $\begin{array}{l}\text { Obtener } \\
\text { cuantitativa de cómo de de } \\
\text { extendidas estaban una serie } \\
\text { de conceptos erróneos o ideas } \\
\text { falsas en física. }\end{array}$ & $\begin{array}{l}\text { El test original fue aplicado } \\
\text { a estudiantes de física } \\
\text { universitarios de primer año } \\
\text { en Sudáfrica. Después } \\
\text { sobre: } 334 \text { estudiantes de } \\
\text { ciencias físicas de niveles } \\
\text { equivalentes al O-level y A- } \\
\text { level de escuelas blancas. } \\
126 \text { de escuelas públicas } \\
\text { del mismo nivel y } 65 \\
\text { profesores. }\end{array}$ & \\
\hline $\begin{array}{l}\text { Watts y } \\
\text { Zilberszta jn. } \\
1981\end{array}$ & $\begin{array}{l}\text { Conocer: a) la comprensión de } \\
\text { los alumnos acerca de la teoría } \\
\text { de Newton y en qué medida los } \\
\text { profesores eran conscientes de } \\
\text { ello; b) si los esquemas } \\
\text { alternativos descritos en las } \\
\text { publicaciones eran compartidos } \\
\text { por sus alumnos. }\end{array}$ & $\begin{array}{l}125 \text { alumnos de } \\
\text { comprehensive schools y } \\
\text { sus } 5 \text { profesores. }\end{array}$ & $\begin{array}{l}\text { Cuestionario con formato } \\
\text { de elección múltiple. Al final } \\
\text { de cada cuestión se dejaba } \\
\text { un espacio donde se pedía } \\
\text { al alumno incluir una razón } \\
\text { para su respuesta. }\end{array}$ \\
\hline $\begin{array}{l}\text { Grunstone y } \\
\text { White, } 1981\end{array}$ & $\begin{array}{l}\text { Evaluar el nivel de comprensión } \\
\text { de los alumnos acerca del } \\
\text { concepto de gravedad y } \\
\text { principios de la mecánica. }\end{array}$ & $\begin{array}{l}\text { Estudiantes de Física de } 1^{\mathrm{er}} \\
\text { de universidad. }\end{array}$ & $\begin{array}{l}\text { Pruebas de papel y lápiz } \\
\text { con demostraciones. Se } \\
\text { pedía al alumno que } \\
\text { escribiese sobre sus } \\
\text { prediciones, observaciones } \\
\text { y que las comparase. }\end{array}$ \\
\hline Watts, 1982 & $\begin{array}{l}\text { Describir los esquemas } \\
\text { conceptuales alternativos de } \\
\text { los niños sobre gravedad. } \\
\text { Proporcionar a los profesores } \\
\text { rápidas y útiles formas de } \\
\text { penetrar en el pensamiento de } \\
\text { los niños. }\end{array}$ & $\begin{array}{l}20 \text { alumnos de } \\
\text { sexto de } r \text { escuelas a } \\
\text { secundarias de Londres } \\
\text { entre } 12 \text { y } 17 \text { años. }\end{array}$ & $\begin{array}{l}\text { Entrevistas personales de } \\
40 \text { minutos utilizando } \\
\text { tarjetas con dibujos de } \\
\text { líneas simples } \\
\text { representando diversas } \\
\text { situaciones donde el } \\
\text { concepto de fuerza es } \\
\text { posible o no el aplicarlo. }\end{array}$ \\
\hline Watts, 1983 & $\begin{array}{l}\text { Describir las concepciones de } \\
\text { los más jóvenes sobre fuerza. }\end{array}$ & $\begin{array}{l}20 \text { alumnos entre } 11 \text { y } 18 \\
\text { años del área urbana de } \\
\text { Londres. }\end{array}$ & $\begin{array}{l}\text { Entrevistas sobre ejemplos } \\
\text { (dibujos esquemáticos) } \\
\text { entrevistados. }\end{array}$ \\
\hline $\begin{array}{l}\text { Maloney, } \\
1984\end{array}$ & 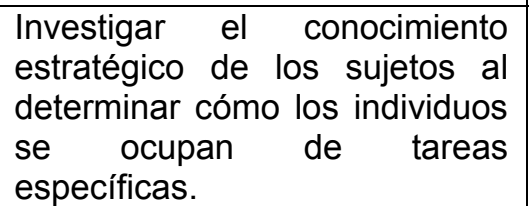 & $\begin{array}{l}112 \text { estudiantes de High } \\
\text { Schools. }\end{array}$ & $\begin{array}{l}\text { Test de elección múltiple. } \\
\text { Una vez completado el } \\
\text { cuestionario se les pedía } \\
\text { escribir una explicación. }\end{array}$ \\
\hline Ivowi, 1984 & $\begin{array}{l}\text { Estudiar la extensión en que se } \\
\text { dan una serie de errores } \\
\text { conceptuales en física entre } \\
\text { los estudiantes de escuela } \\
\text { secundaria y entre sus } \\
\text { profesores que permitan sugerir } \\
\text { posibles causas y soluciones. }\end{array}$ & $\begin{array}{l}258 \text { estudiantes de quinto } \\
\text { curso ( } 15-17 \text { años) de } \\
\text { ocho escuelas secundarias } \\
\text { de Nigeria. } 10 \text { profesores } \\
\text { de física de estas escuelas. }\end{array}$ & $\begin{array}{l}\text { Test de lápiz y papel con } \\
\text { ítems de elección múltiple } \\
\text { (las elecciones para cada } \\
\text { cuestión contenían algunos } \\
\text { errores de conceptos } \\
\text { conocidos o sospechados). }\end{array}$ \\
\hline $\begin{array}{l}\text { Ruggiero y } \\
\text { otros, } 1985\end{array}$ & $\begin{array}{l}\text { Encontrar "esquemas } \\
\text { espontáneos" que muestren la } \\
\text { relación entre peso, aire y } \\
\text { gravedad. }\end{array}$ & $\begin{array}{l}\left.\text { Utiliza tres muestras: } 1^{a}\right) 22 \\
\text { alumnos en el último año } \\
\text { de una escuela media } \\
\left.\text { italiana (12-13 años), } 2^{\text {a }}\right) 8 \\
\text { alumnos de las anteriores. } \\
\left.3^{\mathrm{a}}\right) 40 \text { alumnos de la misma } \\
\text { escuela. }\end{array}$ & $\begin{array}{lrr}\text { Cuestiones } & \text { abiertas } & \text { de } \\
\text { lápiz y papel } & \text { que } & \text { se } \\
\text { proponían } & \text { oralmente } \\
\text { después de } & \text { una } \\
\text { demostración } & \text { o iban } \\
\text { acompañadas de un dibujo } \\
\text { aclaratorio. }\end{array}$ \\
\hline
\end{tabular}




\begin{tabular}{|c|c|c|c|}
\hline $\begin{array}{l}\text { Autor/es } \\
\text { año }\end{array}$ & $\begin{array}{c}\text { Pretensiones u objetivos } \\
\text { de trabajo }\end{array}$ & Muestra & $\begin{array}{c}\text { Técnica de recogida } \\
\text { de datos }\end{array}$ \\
\hline $\begin{array}{l}\text { Terry } y \\
\text { otros, } 1985\end{array}$ & $\begin{array}{l}\text { Averiguar que comprenden los } \\
\text { niños sobre fuerzas y equilibrio } \\
\text { estático. Buscar estrategias de } \\
\text { enseñanza. }\end{array}$ & $\begin{array}{l}\text { Alumnos de comprehensive } \\
\text { schools: } \mathrm{N}=57 \text { (año } 3 \text { ): No } \\
\text { habían recibido instrucción } \\
\text { sobre la } 1^{\mathrm{a}} \text { ni la } 3^{\mathrm{a}} \text { ley de } \\
\text { Newton. } \mathrm{N}=46 \text { (año } 4 \text { ): Se } \\
\text { les había intrioducido en la } \\
1^{\mathrm{a}} \text { y } 2^{\mathrm{a}} \text { ley. } \mathrm{N}=55 \text { (año } 5 \text { ): } \\
\text { habían recibido instrucción } \\
\text { sobre las tres leyes de } \\
\text { Newton. }\end{array}$ & $\begin{array}{l}\text { Pruebas de lápiz y papel } \\
\text { donde se presentan } \\
\text { diagramas. }\end{array}$ \\
\hline $\begin{array}{lr}\text { Terry } & y \\
\text { Jones, } 1986\end{array}$ & $\begin{array}{l}\text { Investigar algunas de las } \\
\text { dificultades conceptuales que } \\
\text { encuentran los estudiantes con } \\
\text { la tercera ley de Newton y } \\
\text { examinar las implicaciones que } \\
\text { tengan para llevar un cambio } \\
\text { en su comprensión global del } \\
\text { concepto de fuerza. }\end{array}$ & $\begin{array}{l}39 \text { alumnos de } 16 \text { años que } \\
\text { recientemente habían } \\
\text { completado un curso de } \\
\text { física de nivel } O \text {. }\end{array}$ & $\begin{array}{l}\text { Presenta a los alumnos } \\
\text { dibujos que representan } \\
\text { situaciones físicas y les } \\
\text { pide interpretarlas en } \\
\text { términos de la tercera ley } \\
\text { de Newton. }\end{array}$ \\
\hline $\begin{array}{l}\text { Clement, } \\
1989\end{array}$ & $\begin{array}{l}\text { Proponer } \\
\text { teórica yuna organización } \\
\text { observacionales del constructo } \\
\text { anclaje. Presentar algunos } \\
\text { hallazgos para descubrir } \\
\text { anclajes en la instrucción de la } \\
\text { física. }\end{array}$ & $\begin{array}{l}137 \text { estudiantes de High } \\
\text { School de } 14,15 \text { y } 17 \text { años. }\end{array}$ & $\begin{array}{l}\text { Test con } 14 \text { cuestiones de } \\
\text { elección múltiple en cada } \\
\text { una de las cuales también } \\
\text { se pedía al alumno indicar } \\
\text { el grado de confianza en su } \\
\text { respuesta mediante un } \\
\text { número en una escala que } \\
\text { va de cero (suposición } \\
\text { ciega) a tres } \\
\text { (completamente seguro) }\end{array}$ \\
\hline Bar, 1989 & $\begin{array}{l}\text { Probar la capacidad de los } \\
\text { niños para comparar fuerzas y } \\
\text { sugerir un procedimiento para } \\
\text { enseñar mecánica a nivel de } \\
\text { escuela elemental. }\end{array}$ & $\begin{array}{l}120 \text { alumnos de escuela } \\
\text { primaria entre 6-11 años. }\end{array}$ & $\begin{array}{l}\text { Test individual oral que } \\
\text { consta de } 12 \text { problemas } \\
\text { demostración. }\end{array}$ \\
\hline Brown, 1989 & $\begin{array}{l}\text { Aportar argumentos que } \\
\text { apoyen la existencia de una } \\
\text { creencia ingenua general de la } \\
\text { fuerza como una propiedad } \\
\text { innata o adquirida de los } \\
\text { objetos. No se pretende } \\
\text { obtener un listado de } \\
\text { concepciones. }\end{array}$ & 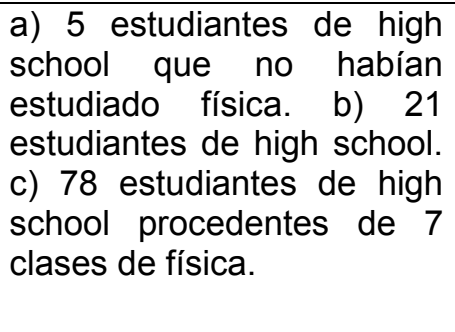 & $\begin{array}{l}\text { a) Entrevistas orales de } \\
\text { preguntas abiertas. b) } \\
\text { Entrevistas con materiales } \\
\text { escritos. c) Test de elección } \\
\text { múltiple con seis problemas } \\
\text { antes y después de la } \\
\text { instrucción. }\end{array}$ \\
\hline $\begin{array}{l}\text { Finegold y } \\
\text { otros, } 1991\end{array}$ & $\begin{array}{l}\begin{array}{l}\text { Determinar el porcentaje de } \\
\text { estudiantes }\end{array} \text { que } \\
\text { consecuentes con sus } \\
\text { creencias sobre las fuerzas que } \\
\text { actúa sobre objetos en reposo } \\
\text { y en movimiento, aplican } \\
\text { consistentemente las leyes } \\
\text { newtonianas correctas y } \\
\text { esquemas conceptuales } \\
\text { alternativos. Para aquellos } \\
\text { estudiantes que parecen ser } \\
\text { inconsecuentes en sus } \\
\text { creencias, identificar sus } \\
\text { categorías de pensamiento y } \\
\text { buscar evidencias de una } \\
\text { lógica subyacente. }\end{array}$ & $\begin{array}{l}333 \text { estudiantes } \\
\text { universitarios, } 144 \\
\text { estudiantes de high school } \\
\text { (grados 11-12). (Todos } \\
\text { habían estudiado física). } 57 \\
\text { estudiantes de high school } \\
\text { (grado 10) que no habían } \\
\text { estudiado física. }\end{array}$ & $\begin{array}{lrr}\text { Test de } & 10 & \text { ítems } \\
\text { administrados } & \text { como una } \\
\text { tarea escrita } & \text { solamente o } \\
\text { acompañada } & \text { de } r \text { una } \\
\text { entrevista. Son preguntas } \\
\text { abiertas acerca de hechos } \\
\text { situacionales } & \text { físicas } \\
\text { concretas. } & \end{array}$ \\
\hline
\end{tabular}




\begin{tabular}{|c|c|c|c|}
\hline $\begin{array}{l}\text { Autor/es } \\
\text { año }\end{array}$ & $\begin{array}{c}\text { Pretensiones u objetivos } \\
\text { de trabajo }\end{array}$ & Muestra & $\begin{array}{c}\text { Técnica de recogida } \\
\text { de datos }\end{array}$ \\
\hline $\begin{array}{l}\text { Kruger y } \\
\text { otros, } 1992\end{array}$ & $\begin{array}{l}\text { Su principal es dar una visión } \\
\text { de los hallazgos relativos a si } \\
\text { los profesores de primaria } \\
\text { comprenden los conceptos de } \\
\text { ciencias lo bastante bien para } \\
\text { presentarlos acertadamente a } \\
\text { los niños. }\end{array}$ & $\begin{array}{l}159 \text { profesores de primaria } \\
\text { ingleses con distinta base } \\
\text { en ciencias y experiencia } \\
\text { profesional. }\end{array}$ & $\begin{array}{l}\text { Entrevistas sobre ejemplos } \\
\text { y acontecimientos a } 20 \\
\text { profesores de primaria. } \\
\text { Después se pasó un } \\
\text { cuestionario de opción } \\
\text { múltiple a una muestra más } \\
\text { amplia. }\end{array}$ \\
\hline Thijs, 1992 & $\begin{array}{l}\text { Evaluar la eficacia de un curso } \\
\text { planeado sobre tuerza en el } \\
\text { que se tienen en cuenta las } \\
\text { preconceptions de los } \\
\text { estudiantes. Identificar qué } \\
\text { estudiantes se benefician del } \\
\text { enfoque constructivista. }\end{array}$ & $\begin{array}{l}190 \text { estudiantes de escuela } \\
\text { secundaria holandesa de } \\
\text { edad media } 15 \text { años. }\end{array}$ & $\begin{array}{l}\text { Test de lápiz y papel con } \\
\text { dibujos. En cada situación, } \\
\text { que corres- pendería a una } \\
\text { cuestión, se preguntan una } \\
\text { serie de subcuestiones, } \\
\text { unas abiertas y otras de } \\
\text { elección múltiple. }\end{array}$ \\
\hline $\begin{array}{l}\text { Kruger y } \\
\text { otros, } 1994\end{array}$ & $\begin{array}{l}\text { Estudiar las interpretaciones } \\
\text { que realizan los alumnos sobre } \\
\text { el concepto de tuerza para } \\
\text { observar si las ideas de los } \\
\text { alumnos sobre tuerza son } \\
\text { coherentes y lógicas, } \\
\text { independientes } \\
\text { contexto(esquemas } \\
\text { alternativos), }\end{array}$ & 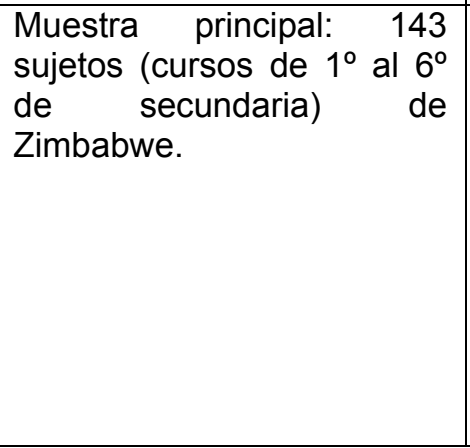 & $\begin{array}{l}\text { Prueba mixta de papel y } \\
\text { lápiz (opción múltiple y } \\
\text { preguntas abiertas). En } \\
\text { todos los casos se } \\
\text { pide seleccionar una } \\
\text { respuesta de un conjunto } \\
\text { de ítems sobre la existencia } \\
\text { de fuerzas y el nivel de } \\
\text { certeza de su elección. En } \\
\text { caso negativo explicar por } \\
\text { qué. }\end{array}$ \\
\hline
\end{tabular}

\section{ANEXO 2: SITUACIONES DE EQUILIBRIO ESTATICO: RESULTADOS DEPENDIENTES DE LOS HECHOS FÍSICOS PRESENTADOS}

\begin{tabular}{|c|c|c|c|}
\hline Autores & $\begin{array}{l}\text { Hechos físicos } \\
\text { presentados }\end{array}$ & $\begin{array}{c}\text { Actividad a realizar } \\
\text { por el alumno }\end{array}$ & Resultados encontrados \\
\hline Helm, 1980 & $\begin{array}{l}\text { Un bloque en reposo } \\
\text { sobre una mesa. }\end{array}$ & \begin{tabular}{|lrr} 
Identificar & & una \\
afirmación & falsa \\
acerca & del & tercer \\
principio & de & la \\
dinámica de & entre \\
una rarioner & de \\
afirmaciones dadas.
\end{tabular} & $\begin{array}{l}\text { En el trabajo se presentan los porcentajes } \\
\text { para las respuestas correctas y de algunos } \\
\text { de los distractores más populares } \\
\text { (conceptos erróneos o ideas falsas). a) Un } \\
\text { bloque en reposo sobre una mesa lisa } \\
\text { tiene dos fuerzas actuando sobre él, la } \\
\text { fuerza gravitacional hacia abajo y la } \\
\text { fuerza de la mesa hacia arriba. o) De la } \\
\text { tercera ley de Newton se deriva que no } \\
\text { existe fricción entre la mesa y el bloque. }\end{array}$ \\
\hline $\begin{array}{l}\text { Gunstone y } \\
\text { White, } 1981\end{array}$ & \begin{tabular}{|lrr|} 
1) Un borrador sobre \\
un libro, que a su vez \\
está & \multicolumn{2}{c}{ sostenido } \\
horizontalmente & a \\
cierta altura sobre el \\
suelo. & Se & quita \\
rápidamente el libro y el \\
borrador se pone en \\
movimiento. & 2) & Un \\
\multicolumn{4}{c}{ muelle } & con \\
escala del que cuelga \\
un cubo de arena que \\
fuesen & llevados & al \\
tejado, & al & monte \\
Kosciusko o al Everest.
\end{tabular} & $\begin{array}{l}\text { 1) a) Explicar porqué } \\
\text { el borrador no se } \\
\text { mueve cuando está } \\
\text { encima del libro, b) } \\
\text { Explicar qué pone al } \\
\text { borrador } \\
\text { movimientor en } \\
\text { Predecir la posición } \\
\text { del puntero de la } \\
\text { escala si el sistema } \\
\text { se colocase en } \\
\text { lugares de diferente } \\
\text { altitud }\end{array}$ & 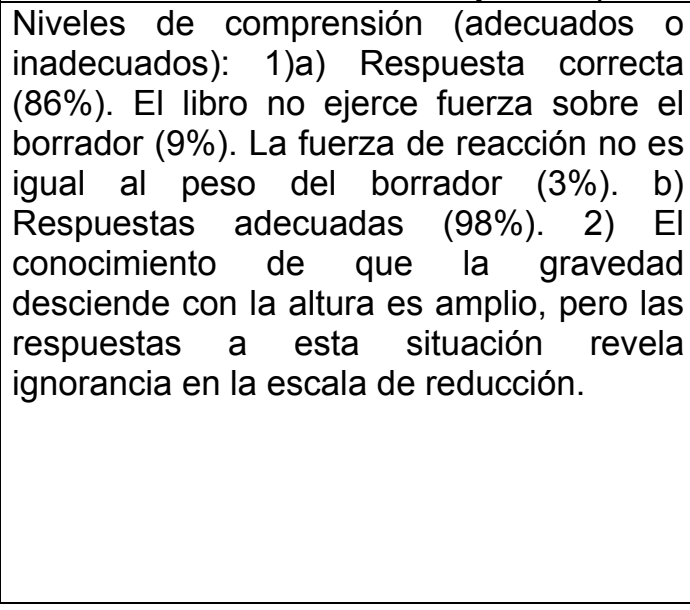 \\
\hline
\end{tabular}




\begin{tabular}{|c|c|c|c|}
\hline \begin{tabular}{|l} 
Watts y \\
Zylbersztajn, \\
1981
\end{tabular} & $\begin{array}{l}\text { 1) Dos personas } \\
\text { impidiendo que rueden } \\
\text { hacia abajo dos coches } \\
\text { iguales sobre la misma } \\
\text { colina, uno en una } \\
\text { posición más alta que } \\
\text { el otro. 2) Dos } \\
\text { linternas colocadas } \\
\text { verticalmente sobre la } \\
\text { mesa, una encendida y } \\
\text { la otra apagada. }\end{array}$ & \begin{tabular}{|l|} 
1) Comparar las fuer- \\
zas ejercidas por los \\
individuos. r r \\
Comparar las fuerzas \\
que tienen las \\
linternas. En todos \\
los casos se pedía \\
dar una explicación.
\end{tabular} & $\begin{array}{l}\text { 1) Opción mayoritaria: La fuerza que tira } \\
\text { del coche hacia abajo es mayor para el que } \\
\text { está más arriba en la montaña. Esquemas } \\
\text { inesperados: - La gravedad se } \\
\text { incrementa con la altura. - La pendiente } \\
\text { es más escarpada en la parte superior del } \\
\text { plano inclinado. 2) Opciones mayoritarias: } \\
\text { - La linterna encendida tendría sobre ella } \\
\text { una fuerza más grande (47\%). - No } \\
\text { existiría diferencia (42\%) Descripción de } \\
\text { las explicaciones de los niños: El lenguaje } \\
\text { de los niños de } 14 \text { años carece de } \\
\text { precisión y sus palabras sostienen } \\
\text { significados globales y generosos. Algunas } \\
\text { explicaciones de los niños: "La linterna que } \\
\text { está encendida tiene más fuerza porque es } \\
\text { necesitada para emitir rayos de luz. La } \\
\text { linterna que tiene energía potencial no } \\
\text { necesita una fuerza tan grande como la } \\
\text { que está encendida". "La linterna } \\
\text { encendida necesita más fuerza porque } \\
\text { está consumiendo energía". "La fuerza de } \\
\text { la energía de la linterna que está } \\
\text { encendida es más grande que la de la que } \\
\text { está apagada" }\end{array}$ \\
\hline Ivowi, 1984 & $\begin{array}{l}\text { Un bloque en reposo } \\
\text { sobre una mesa. }\end{array}$ & 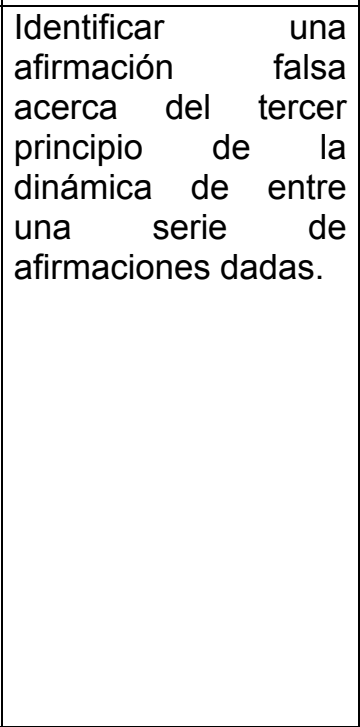 & $\begin{array}{l}\text { Respuestas correctas y concepciones } \\
\text { erróneas: a) Un bloque en reposo sobre } \\
\text { una mesa lisa tiene dos fuerzas } \\
\text { actuando sobre él, la fuerza gravitacional } \\
\text { hacia abajo y la fuerza de la mesa hacia } \\
\text { arriba. b) Ya que no existe movimiento } \\
\text { verticalmente, estas dos fuerzas deben ser } \\
\text { iguales y opuestas. c) De la tercera ley de } \\
\text { Newton se deriva que no existe fricción } \\
\text { entre la mesa y el bloque. d) El bloque está } \\
\text { en equilibrio, e) El sistema pone de } \\
\text { manifiesto el hecho de que las fuerzas } \\
\text { siempre van en parejas. En todos los casos } \\
\text { los autores dan el número de sujetos que } \\
\text { eligen cada opción y se observa que en } \\
\text { algunas cuestiones las respuestas de los } \\
\text { profesores siguen las mismas tendencias } \\
\text { que las de sus alumnos. }\end{array}$ \\
\hline $\begin{array}{l}\text { Terry y Jones, } \\
1986\end{array}$ & $\begin{array}{l}\text { 1) Una persona de pié } \\
\text { en el suelo, }\end{array}$ & $\begin{array}{ll}\text { 1) Identificar } & \text { la } \\
\text { fuerza que según la } \\
\text { tercera ley r de } \\
\text { Newton r está } \\
\text { emparejada con la } \\
\text { fuerza peso. }\end{array}$ & $\begin{array}{l}\text { 1) De las respuestas deduce que: - Las } \\
\text { dos fuerzas de un par de la tercera ley de } \\
\text { Newton actúan sobre el mismo objeto para } \\
\text { mantenerlo en equilibrio (concepción } \\
\text { errónea).-Ausencia de comprensión de } \\
\text { que las fuerzas proceden de interacciones } \\
\text { entre dos objetos y de que pueden ser } \\
\text { descritas por la tercera ley de Newton. }\end{array}$ \\
\hline $\begin{array}{l}\text { Clement y } \\
\text { otros, } 1989\end{array}$ & $\begin{array}{l}\text { 1) Cuando sostienes un } \\
\text { diccionario muy pesado } \\
\text { de } 30 \text { libras sobre la } \\
\text { mano, la gravedad } \\
\text { ejerce una fuerza hacia } \\
\text { abajo de } 30 \text { libras } \\
\text { sobre el diccionario. 2) } \\
\text { Empujar hacia abajo } \\
\text { sobre un muelle } \\
\text { vertical. }\end{array}$ & $\begin{array}{l}\text { 1) ¿Empuja la mano } \\
\text { hacia arriba sobre el } \\
\text { diccionario? } \\
\text { ¿Empuja el muelle } \\
\text { sobre la mano? }\end{array}$ & $\begin{array}{l}\text { Identifica como anclajes de grupo los } \\
\text { siguientes: 1) En el problema del } \\
\text { diccionario, la mano empuja hacia arriba } \\
\text { sobre el diccionario. 3) En el problema del } \\
\text { muelle, el muelle empuja hacia arriba sobre } \\
\text { la mano. }\end{array}$ \\
\hline
\end{tabular}




\begin{tabular}{|c|c|c|c|}
\hline Bar, 1989 & $\begin{array}{|lr|}\text { Problemas } & \text { de } \\
\text { equilibrado } & \text { de } \\
\text { balancines: Se cuelga } \\
\text { un peso de un brazo de } \\
\text { una palanca y se } \\
\text { equilibra dos veces } \\
\text { mediante diferentes } \\
\text { conjuntos de pesos col- } \\
\text { gados en dos puntos } \\
\text { diferentes sobre el otro } \\
\text { brazo de la palanca. Se } \\
\text { quitan los pesos que } \\
\text { equilibraban y se } \\
\text { equilibra presionando } \\
\text { con el dedo en los } \\
\text { mismos dos puntos }\end{array}$ & \begin{tabular}{|lrr} 
Comparar & la \\
intensidad & de las \\
fuerzas de presión \\
en esos dos puntos y \\
expresar la relación \\
entre & ellas \\
numéricamente. \\
Explicar cómo se \\
dedujo esa relación \\
numérica,
\end{tabular} & $\begin{array}{l}\text { a) Respuestas cualitativas. b) Respuestas } \\
\text { de esquema aditivo (contaban el número } \\
\text { de agujeros o el número de pesos y los } \\
\text { sumaban o los restaban para dar la } \\
\text { respuesta). c) Respuestas de tipo } \\
\text { multiplicativo-aditivo. d) Respuestas de tipo } \\
\text { multiplicativo, e) Respuestas especiales. } \\
\text { Los niños de escuela elemental no } \\
\text { identifican peso y fuerza pero son capaces } \\
\text { de usar la relación entre el número de } \\
\text { pesos para comparar fuerzas. A partir de } \\
\text { los } 10 \text { años, la mitad de los participantes } \\
\text { eran capaces de dar la respuesta } \\
\text { cuantitativa correcta. El porcentaje de } \\
\text { respuestas correctas es independiente del } \\
\text { número de pesos colgados con tal de que } \\
\text { sean números enteros. }\end{array}$ \\
\hline $\begin{array}{ll}\text { Kruger y } \\
\text { otros, } 1992\end{array}$ & $\begin{array}{ll}\text { 1) Un } & \text { hombre } \\
\text { intentando mover un } \\
\text { coche pero el coche no } \\
\text { se mueve, 2) } & \text { Una caja } \\
\text { sobre una pendiente La } \\
\text { caja no se mueve. } \\
\text { Un hombre sobre la } \\
\text { luna. }\end{array}$ & $\begin{array}{l}\text { Identificar la } \\
\text { presencia o ausencia } \\
\text { de fuerzas sobre el } \\
\text { objeto (coche, caja) o } \\
\text { sobre el individuo. } \\
\text { Dar una explicación. }\end{array}$ & $\begin{array}{l}\text { Hallazgos del cuestionario de fuerzas en } \\
\text { relación a concepciones erróneas en } \\
\text { relación con las fuerzas implicadas en } \\
\text { situaciones estáticas: - Muchos } \\
\text { profesores no estaban seguros de qué se } \\
\text { considera como fuerza en situaciones } \\
\text { estáticas. - Muchos profesores no } \\
\text { reconocen la fuerza de reacción que una } \\
\text { mesa o el suelo ejerce sobre los objetos. } \\
-25 \% \text { de la muestra rechaza la existencia } \\
\text { de la fuerza de reacción en todas las } \\
\text { situaciones del cuestionario y por encima } \\
\text { del } 50 \% \text { rechaza su existencia en el caso } \\
\text { de un coche estacionario. - Sobre el } 40 \% \\
\text { estaba inseguro del estatus del peso como } \\
\text { tuerza o rechazaba que era una fuerza. } \\
\text { Más de la mitad no identificaba peso } \\
\text { con gravedad. }- \text { La idea de tuerza neta } \\
\text { era nueva para muchos profesores. }\end{array}$ \\
\hline
\end{tabular}

\section{ANEXO 3: SITUACIONES DE EQUILIBRIO ESTÁTICO: RESULTADOS INDEPENDIENTES DE LOS HECHOS FÍSICOS PRESENTADOS}

\begin{tabular}{|c|c|c|c|}
\hline Autores & $\begin{array}{l}\text { Hechos físicos } \\
\text { presentados }\end{array}$ & $\begin{array}{l}\text { Actividad a realizar } \\
\text { por el alumno }\end{array}$ & Resultados encontrados \\
\hline Watts, 1982 & $\begin{array}{l}\text { 1) Un individuo que } \\
\text { pasea sosteniendo un } \\
\text { hilo en cuyo extremo } \\
\text { hay un globo. 2) Dos } \\
\text { linternas similares una } \\
\text { encendida y la otra } \\
\text { apagada colocadas } \\
\text { verticalmente apuntando } \\
\text { al techo. 3) Un libro } \\
\text { sobre una mesa. }\end{array}$ & $\begin{array}{l}\text { Identificar si existen o } \\
\text { no tuerzas en cada } \\
\text { situación. }\end{array}$ & $\begin{array}{l}\text { Esquemas alternativos: } \\
\text { - La gravedad es una fuerza que } \\
\text { requiere un medio a través del } \\
\text { cual actuar. } \\
\text { - La gravedad es una tuerza } \\
\text { grande (que lo mantiene todo } \\
\text { sobre el suelo). } \\
\text { - } \\
\text { La gravedad no es lo mismo que } \\
\text { el peso pero pueden actuar } \\
\text { conjuntamente para mantener las } \\
\text { cosas abajo. } \\
\text { - La gravedad es selectiva - no } \\
\text { actúa sobre todas las cosas de la } \\
\text { misma forma ni sobre las } \\
\text { mismas cosas de la misma forma } \\
\text { todo el tiempo. }\end{array}$ \\
\hline
\end{tabular}




\begin{tabular}{|c|c|c|c|}
\hline Watts, 1983 & $\begin{array}{l}\text { 1) Un niño con un globo } \\
\text { 2) Dos linternas, una } \\
\text { que ilumina y otra no } \\
\text { situadas verticalmente } \\
\text { sobre una mesa } \\
\text { apuntando al techo. } \\
\text { 3) Un libro encima de } \\
\text { una mesa. }\end{array}$ & $\begin{array}{l}\text { Identificar la presencia } \\
\text { o ausencia de fuerzas } \\
\text { en cada situación. Dar } \\
\text { una explicación, }\end{array}$ & \begin{tabular}{|l} 
Esquemas alternativos: \\
- Fuerzas de configuración: Los \\
objetos retenidos en una posición \\
tienen fuerza. Tienen un sentido \\
similar a la idea del físico de \\
energía potencial. \\
Fuerzas sustanciales: Fuerza \\
como propiedad de una sustancia \\
que es transmitida a todas las \\
partes de la misma y que actúa \\
en la superficie con otros objetos. \\
Necesita alguna sustancia a \\
través de la cual operar. Más bien \\
similar a la noción física de \\
presión. Las fuerzas son acciones \\
positivas que son efectivas \\
cuando entran en contacto con los \\
objetos. Son positivas en el \\
sentido de que los \\
acontecimientos tienen resultados \\
claros, abiertos y obvios. Tiene \\
lugar una actividad a gran escala.
\end{tabular} \\
\hline $\begin{array}{l}\text { Maloney, } \\
1984\end{array}$ & $\begin{array}{l}\text { Dos bloques } \\
\text { enganchados uno a otro } \\
\text { o bien adosados están } \\
\text { en reposo sobre una } \\
\text { superficie horizontal } \\
\text { siendo sus masas } \\
\text { iguales o distintas. }\end{array}$ & $\begin{array}{l}\text { Comparar la fuerza } \\
\text { que ejerce el bloque A } \\
\text { sobre el B con la que } \\
\text { ejerce B sobre A. }\end{array}$ & $\begin{array}{l}\text { Las posibles reglas (modelos o estrategias } \\
\text { de razonamiento) pueden clasificarse en } \\
\text { categorías. Las siguientes categorías y } \\
\text { reglas, tienen en cuenta las } 2 / 3 \text { partes de } \\
\text { las respuestas: } \\
\text { - Categoría 1: Todos los tipos de } \\
\text { movimiento (reposo, mov. con } \\
\text { velocidad constante y aceleración } \\
\text { constante) son tratados de una } \\
\text { forma similar. 1a) La masa es el } \\
\text { único determinante de todos los } \\
\text { estados (reposo, movimiento con } \\
\text { velocidad constante o con } \\
\text { aceleración constante). La masa } \\
\text { más grande ejerce una tuerza } \\
\text { más grande. } \\
\text { Categoría 2: El reposo es tratado } \\
\text { como único pero el movimiento } \\
\text { con velocidad o aceleración } \\
\text { constante son tratados de la } \\
\text { misma forma. } 2 a \text { ) En reposo las } \\
\text { tuerzas son iguales, pero para } \\
\text { sistemas en movimiento, masas } \\
\text { mayores ejercen tuerzas más } \\
\text { grandes. 2b) En reposo las } \\
\text { tuerzas son iguales, pero para } \\
\text { sistemas en movimiento la causa } \\
\text { (bloque que está empujando e } \\
\text { tirando del otro en la dirección del } \\
\text { movimiento) ejerce una fuerza } \\
\text { más grande. } \\
\text { Categoría } 3 \text { : Reposo y } \\
\text { movimiento con velocidad } \\
\text { constante son tratados de forma } \\
\text { similar pero el movimiento con } \\
\text { aceleración o constante es } \\
\text { considerada como un caso. }\end{array}$ \\
\hline
\end{tabular}




\begin{tabular}{|c|c|c|c|}
\hline Autores & $\begin{array}{l}\text { Hechos físicos } \\
\text { presentados }\end{array}$ & $\begin{array}{c}\text { Actividad a realizar } \\
\text { por el alumno }\end{array}$ & Resultados encontrados \\
\hline $\begin{array}{l}\text { Ruggiero y } \\
\text { otros, } 1985\end{array}$ & 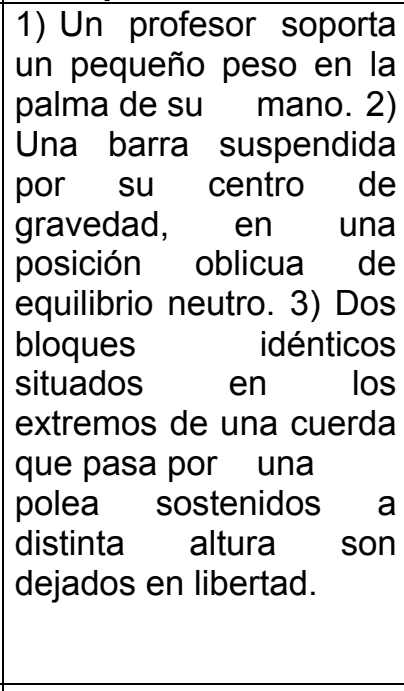 & $\begin{array}{llr}\text { 1) Explicar } & \text { por qué no } \\
\text { cae el } & \text { peso. } & 2 \text { ) } \\
\text { Explicar la } & \text { situación y } \\
\text { predecir } & \text { lo } & \text { que } \\
\text { ocurriría } & \text { si } & \text { se } \\
\text { colocasen } & \text { dos } & \text { pesos } \\
\text { iguales } & \text { en } & \text { los } \\
\text { extremos de la } & \text { barra. } \\
\text { 3) Predecir lo } & \text { que } \\
\text { ocurriría al } & \text { dejarlos en } \\
\text { libertad. } & & \end{array}$ & $\begin{array}{l}\text { Las respuestas a estas cuestiones no } \\
\text { proporcionaron información significativa } \\
\text { sobre la relación peso-aire-gravedad. Las } \\
\text { respuestas eran prácticamente las mismas } \\
\text { para todos los niños: los niños se retiren a } \\
\text { las experiencias comunes de que las } \\
\text { cosas que reposan sobre un soporte no } \\
\text { caen y los objetos permanecen } \\
\text { normalmente en equilibrio en posición } \\
\text { horizontal y en el caso de la polea las } \\
\text { respuestas son muy diversas (no estando } \\
\text { en desacuerdo con los resultados de } \\
\text { Watts y Zylbersztajn). Esto } \\
\text { último sugiere que el esquemá para el } \\
\text { equilíbrío de un objeto (barra) podría ser } \\
\text { diferente al esquema para los objetos en } \\
\text { la polea. Requeriría nuevo estudio. }\end{array}$ \\
\hline $\begin{array}{l}\text { Terry y otros, } \\
1989\end{array}$ & $\begin{array}{l}\text { 1) Una caja en reposo } \\
\text { sobre una mesa. } \\
\text { a) Una caja } \\
\text { suspendida de un } \\
\text { muelle. } \\
\text { b) Una caja } \\
\text { sostenida encima } \\
\text { de la mano. }\end{array}$ & $\begin{array}{l}\text { 1) Explicar qué } \\
\text { mantiene a la caja } \\
\text { en reposo sobre la } \\
\text { mesa. Identificar } \\
\text { las fuerzas que } \\
\text { actúan sobre la } \\
\text { caja. Explicar si la } \\
\text { mesa ejerce } \\
\text { alguna fuerza } \\
\text { sobre la caja. } \\
\text { 2) Identificar las } \\
\text { fuerzas que actúan } \\
\text { sobre la caja. }\end{array}$ & $\begin{array}{l}\text { 1) Idenfificar: a) Fuerza de la gravedad: es } \\
\text { una fuerza que actúa hacia abajo sobre } \\
\text { la superficie del objeto. b) No actúan } \\
\text { fuerzas externas, c) La caja ejerce } \\
\text { fuerza sobre la mesa pero pocos } \\
\text { identifican que la mesa ejerce otra } \\
\text { fuerza sobre la caja, a pesar de que } \\
\text { muchos hacian referencia a la tercera } \\
\text { ley de Newton. Esquema conceptual: } \\
\text { considerar la gravedad de una forma } \\
\text { similar a lo que piensan de la fuerza } \\
\text { ejercida por el aire sobre un objeto, } \\
\text { como la fuerza hacia abajo que actúa } \\
\text { sobre ha superficie del objeto. } \\
\text { 2) } 2 \text { a) Identifican dos tuerzas: hacia abajo } \\
\text { debida a la gravedad y hacia arriba } \\
\text { debida al muelle. 2b) } 40 \% \text { identifican } \\
\text { dos fuerzas. El porcentaje de } \\
\text { respuestas correctas au menta con } \\
\text { la instrucción recibida. }\end{array}$ \\
\hline Brown,1989 & $\begin{array}{l}\text { Un bloque de acero de } \\
90 \mathrm{Kg} \text { situado sobre otro } \\
\text { más pequeño de } 18 \mathrm{Kg} \text {. }\end{array}$ & $\begin{array}{l}\text { Comparar la tuerza } \\
\text { que ejerce A sobre B } \\
\text { con la que ejerce B } \\
\text { sobre A. }\end{array}$ & $\begin{array}{l}\text { Seis opciones de respuesta del ítem ( de } \\
\text { las cuales sólo algunas de las incorrectas } \\
\text { parecen responder a la visión de fuerza } \\
\text { como una propiedad innata o adquirida } \\
\text { por el objeto): (1) A ejerce una fuerza más } \\
\text { grande. (2) B ejerce una fuerza más } \\
\text { grande. (3) Las tuerzas son iguales. (4) } \\
\text { Sólo A ejerce fuerza. (5) Sólo B ejerce } \\
\text { fuerza. (6) Nadie ejerce fuerza. El } \\
\text { porcentaje de respuestas) correctas e } \\
\text { incorrectas) consistente con un concepto } \\
\text { de fuerza como una propiedad de los } \\
\text { objetos eran del } 54 \% \text { y } \\
46 \% \text { en el pre-test y post-test } \\
\text { respectivamente. }\end{array}$ \\
\hline $\begin{array}{l}\text { Finegold y } \\
\text { Gorsky, } 1991\end{array}$ & $\begin{array}{l}\text { 1) Un péndulo } \\
\text { estacionario. } \\
\text { 2) Un libro en reposo } \\
\text { sobre una mesa pla- } \\
\text { na. }\end{array}$ & \begin{tabular}{|lrr} 
Identificar las fuerzas \\
que actúan & sobre los \\
objetos & en & las \\
distintas & situaciones \\
nombrándolas & e \\
indicando & mediante \\
flechas & sus
\end{tabular} & 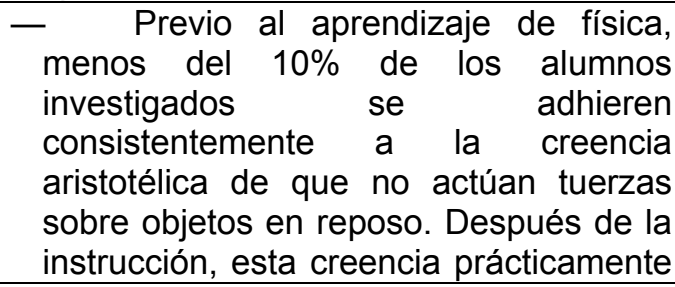 \\
\hline
\end{tabular}




\begin{tabular}{|c|c|c|c|}
\hline & & direcciones. & $\begin{array}{l}\text { no existe. } \\
\text { Gilberf y Watts (1983) señalaron } \\
\text { que muchos investigadores recogían } \\
\text { que la creencia aristotélica «no existen } \\
\text { fuerzas sobre objetos en reposo» es una } \\
\text { esquema alternativo común entre los } \\
\text { alumnos que no han estudiado física. } \\
\text { Nuestros hallazgos sugieren, sin } \\
\text { embargo, que esta creencia no es ni } \\
\text { común ni un esquema alternativo ) en } \\
\text { términos de Engel y Driver, 1982). } \\
\text { - En el trabajo se recogen los } \\
\text { porcentajes de alumnos que se adhieren } \\
\text { a creencias inconsistentes sobre las } \\
\text { fuerzas actuantes sobre objetos en } \\
\text { reposo. } \\
\text { Estudia también si los estudiantes } \\
\text { incluyen o excluyen consistentemente } \\
\text { fuerzas que se oponen a la de la } \\
\text { gravedad en objetos en reposo y para los } \\
\text { mismos objetos en movimiento. El } 79 \% \\
\text { de los estudiantes universitarios y de } \\
\text { high school de nivel avanzado se } \\
\text { adherian a creencias consistentes } \\
\text { (correctas o incorrectas). Sin embargo, } \\
\text { los alumnos que habían estudiado Física } \\
\text { a nivel ordinario y los que no habían } \\
\text { estudiado Física eran inconsistentes en } \\
\text { señalar fuerzas reactivas. } \\
\text { Probablemente existan esquemas } \\
\text { conceptuales en las mentes de los } \\
\text { estudiantes como almacenes para el } \\
\text { contenido de Física, pero no } \\
\text { proporcionan una perspectiva desde la } \\
\text { cual sea posible predecir las creencias } \\
\text { de los estudiantes sobre el } \\
\text { comportamiento físico. }\end{array}$ \\
\hline Thijs, 1992 & $\begin{array}{l}\text { 1) Una manzana } \\
\text { colgada de la rama } \\
\text { del árbol. } \\
\text { 2) Una manzana que } \\
\text { yace sobre el suelo. }\end{array}$ & $\begin{array}{l}\text { Identificar la presencia } \\
\text { o ausencia de fuerzas. } \\
\mathrm{Si} \text { el alumno contesta } \\
\text { que no hay fuerzas, } \\
\text { dar una explicación. Si } \\
\text { contesta que sí, } \\
\text { identificarlas. De las } \\
\text { que considere que } \\
\text { están presentes, } \\
\text { describirlas en cuanto } \\
\text { a dirección e e } \\
\text { intensidad. }\end{array}$ & $\begin{array}{l}\text { Para elaborar el cuestionario utiliza } \\
\text { términos extraídos de investigaciones } \\
\text { de otros autores bajo los cuales subyace } \\
\text { una concepción errónea particular. } \\
\text { Estas concepciones erróneas son: a) En } \\
\text { situaciones de reposo: } \\
\text { 1.No hay fuerzas presentes o sólo la } \\
\text { fuerza de la gravedad. } \\
\text { 2. Si hay varias fuerzas presentes, una de } \\
\text { ellas es dominante. Pero en realidad lo } \\
\text { que le interesa es ver cómo evoluciona } \\
\text { el porcentaje de respuestas correctas } \\
\text { como consecuencia de una secuencia } \\
\text { de enseñanza determinada. }\end{array}$ \\
\hline $\begin{array}{l}\text { Kuiper y } \\
\text { Mondlane, } \\
1994\end{array}$ & $\begin{array}{l}\text { Un bloque de madera } \\
\text { yace en reposo sobre } \\
\text { una mesa. El mismo } \\
\text { problema se proponía } \\
\text { cuatro veces sólo que } \\
\text { situado en contextos } \\
\text { diferentes. }\end{array}$ & \begin{tabular}{|l|} 
Identificar la presencia \\
o ausencia de fuerzas \\
actuando sobre el \\
trozo de madera. Si la \\
respuesta es sí, definir \\
el grado de certeza, \\
dibujar mediante \\
flechas las fuerzas y \\
escribir su nombre. Si \\
la respuesta es no,
\end{tabular} & $\begin{array}{l}\text { Los tres principales tipos de respuestas } \\
\text { para situaciones de reposo eran: } \\
\text { - Correcta: Actúan la fuerza de la } \\
\text { gravedad y la normal. } \\
\text { - Intermedia: Sólo actúa la gravedad } \\
\text { - Intuitiva: No actúan fuerzas. Dentro } \\
\text { de un área problema (reposo (A), } \\
\text { objetos en movimiento (B), objetos } \\
\text { lanzados (C) y colisiones (D)), los } \\
\text { estudiantes han usado en gran }\end{array}$ \\
\hline
\end{tabular}




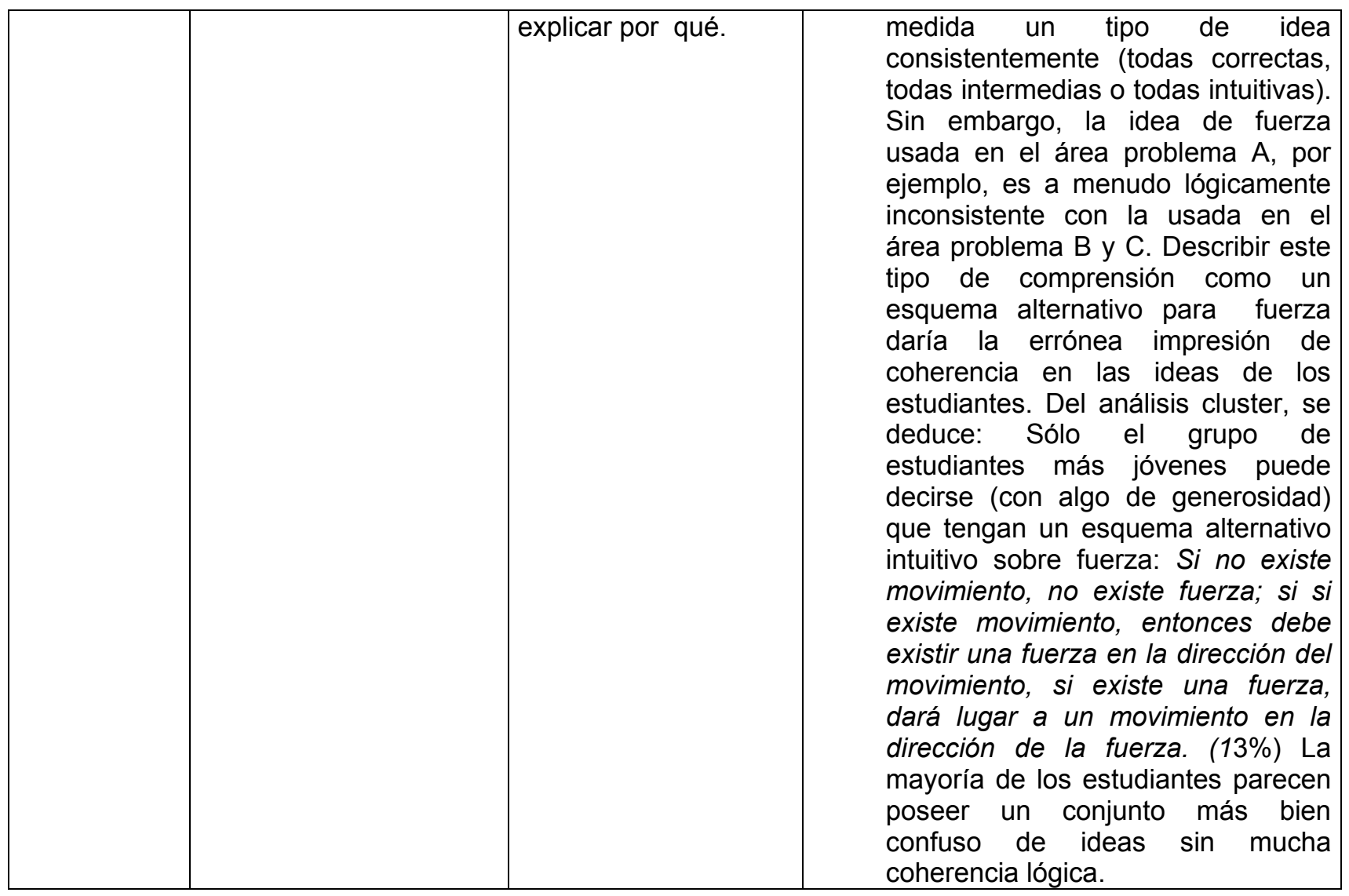

